\title{
Regenerative effects of hyperbaric oxygen therapy and platelet-rich plasma on the osteochondral defects of rats
}

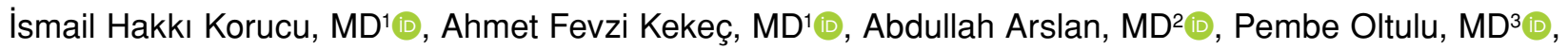

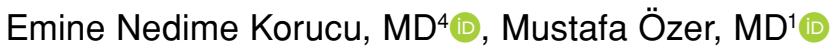 \\ ${ }^{1}$ Department of Orthopedics and Traumatology, Necmettin Erbakan University, Meram Faculty of Medicine, Konya, Turkey \\ ${ }^{2}$ Department of Underwater and Hyperbaric Medicine, Necmettin Erbakan University, Meram Faculty of Medicine, Konya, Turkey \\ ${ }^{3}$ Departmant of Pathology, Necmettin Erbakan University, Meram Faculty of Medicine, Konya, Turkey \\ ${ }^{4}$ Department of Molecular Biology and Genetics, Necmettin Erbakan University, Faculty of Science, Konya, Turkey
}

The damage of joint cartilage is one of the most common problems in the field of orthopedics. Acute and repetitive loads are known to damage the articular cartilage, further resulting in pain, effusion, osteoarthritis, and joint dysfunction. In the present times, the treatment of osteochondral lesions still poses a lot of challenges; one of which is a difficult road to recovery. In most cases, the full-thickness cartilage defect is not healed properly. ${ }^{[1,2]}$ Generally, the healing process results in the formation of fibrous cartilage instead of the hyaline cartilage. Instead of a spontaneous recovery, various treatments have been attempted to rectify the condition. ${ }^{[3]}$ The integration of autogenic or allogenic grafts with hyaline cartilage on the defects has been problematic. Although the cultivation of mesenchymal stem cells and chondrocytes has yielded good results, they are expensive and it is difficult to form a cell culture with them. ${ }^{[4]}$ Despite these treatments, osteoarthritis and total joint prosthesis still occur in patients..$^{[5-7]}$ Therefore, there is an urgent need for treatment methods to increase the regeneration of cartilage,

Received: December 11, 2019

Accepted: February 18, 2020

Published online: June 18, 2020

Correspondence: Ahmet Fevzi Kekeç, MD. Necmettin Erbakan

Üniversitesi, Meram Tıp Fakültesi, Ortopedi ve Travmatoloji

Anabilim Dalı, 42080 Meram, Konya, Türkiye.

E-mail: afkekec@hotmail.com

Doi: $10.5606 /$ ehc. 2020.72592

Citation: Korucu IH, Kekeç AF, Arslan A, Oltulu P, Korucu EN, Özer M. Regenerative effects of hyperbaric oxygen therapy and platelet-rich plasma on the osteochondral defects of rats. Jt Dis Relat Surg 2020;31(2):260-266.

\section{ABSTRACT}

Objectives: This study aims to investigate the effects of hyperbaric oxygen (HBO) therapy and platelet-rich plasma (PRP) on the regeneration of osteochondral defects of the rats, and the synergistic effect of this combined treatment.

Materials and methods: This randomized, controlled, and interventional animal study was conducted between May 2014 and August 2014 Osteochondral regeneration was evaluated in four treatment groups (control, $\mathrm{PRP}, \mathrm{HBO}$, and $\mathrm{HBO}+\mathrm{PRP}$ groups) at the $30^{\text {th }}$ day after iatrogenic injury. Thirty-two female Wistar albino rats (weighing 248-305 g) underwent arthrotomy and osteochondral surgery on left knees. The regenerations of defects were then examined histologically by the modified version of O’Driscoll score.

Results: Groups that were treated with either HBO or PRP alone regenerated significantly better than the control group $(p=0.01)$, while no significant difference was found between the HBO- and PRP-treated groups $(\mathrm{p}>0.05)$. The defects in group 4 (treated with both HBO and PRP) regenerated significantly better than the control group, the HBO-treated group alone, and the PRP-treated group alone $(\mathrm{p}=0.01)$.

Conclusion: The results of this study showed a synergistic effect of HBO and PRP on knee cartilage regeneration. However, the possible underlying mechanisms should be the subject of future researches. The aggregation and activation of growth factors released from platelets whose activation is increased in the hyperbaric environment may explain this effect. This may result in a better regeneration than the effect of PRP or HBO alone.

Keywords: Cartilage regeneration, hyperbaric oxygen therapy, osteochondral defect, platelet-rich plasma.

ultimately promoting the recovery with hyaline cartilage.

One of the methods that are used to accelerate the tissue regeneration involves the use of autologous blood products, particularly platelet-rich plasma (PRP). After this stimulation, chondrocytes have been 
observed to increase the production of proteoglycan and collagen, ultimately providing healing on the tissue that resembles the histological and biomechanical properties of a hyaline cartilage. ${ }^{[8]} \mathrm{On}$ the site of its application, PRP facilitates the secretion of many cytokines and growth factors that stimulate the healing and regeneration of tissues. After its proven efficacy in animal experiments, ${ }^{[9-13]}$ it has been used in clinical practice in recent years. Previous studies have also shown the benefits of PRP in the healing of cartilage. ${ }^{[14-21]}$ Platelet-rich plasma has become a popular choice in recent years because of its positive contribution in the healing of tissues. ${ }^{[9-27]}$

There are many studies present in the literature that demonstrate the effects of hyperbaric oxygen (HBO) treatment on tissue regeneration, particularly in diabetic foot wounds. ${ }^{[28-31]}$ Hyperbaric oxygen treatment is effective in the process of tissue healing with various mechanisms of action. However, there are very few studies in the literature regarding the use of $\mathrm{HBO}$ in osteochondral defects. It has been reported that HBO treatment is also effective in the healing of osteochondral lesions in rabbits. ${ }^{[22]}$

In this study, we aimed to investigate the effects of HBO therapy and PRP on the regeneration of osteochondral defects of the rats, and the synergistic effect of this combined treatment. ${ }^{[32]}$

\section{MATERIALS AND METHODS}

This randomized, controlled, and interventional animal study was conducted at the Animal Research Center of Necmettin Erbakan University between May 2014 and August 2014 with the formal approval of the Ethics Committee for Animal Research. In total, 32 female Wistar albino rats (weighing 248-305 g) were used in this study. The rats were kept under the natural day/night cycle at room temperature and allowed to eat standard pellet feed and drink water ad libitum.

The rats were divided into four groups with each group having a total of eight rats. The groups were distinguished as follows: No intervention was performed on the rats of group 1 after the creation of osteochondral defects. Group 2 rats were treated with $\mathrm{HBO}$ for 90 minutes at 2.4 atmospheres absolute (ATA) pressure during six days of a week for a total period of four weeks. Group 3 rats were treated with a single dose of $100 \mu \mathrm{L}$ PRP to the knee joint space on the day of the procedure after the creation of osteochondral defect. After the creation of osteochondral defect, group 4 rats were treated with $\mathrm{HBO}$ for 90 minutes at 2.4 ATA pressure during six days of a week for all weeks from the postoperative first day. Also, $100 \mu \mathrm{L}$ PRP was applied on the joint space on the day of procedure.

All surgical procedures were performed under sterile conditions. For intraperitoneal anesthesia, $50 \mathrm{mg} / \mathrm{kg}$ ketamine hydrochloride (Ketalar vial, Eczacibaşı, Istanbul, Turkey) and $5 \mathrm{mg} / \mathrm{kg}$ xylazine hydrochloride (Rompun; Bayer Vital $\mathrm{GmbH}$, Leverkusen, Germany) were administered intraperitoneally in the rats. Surgical field antisepsis was achieved with povidone-iodine after placing the rats on the fixation board in the supine position. An osteochondral defect of $2 \mathrm{~mm}$ in diameter and $2 \mathrm{~mm}$ in depth was created on the patellar groove in the left knee by $2 \mathrm{~mm}$ Kirschner wire by using the medial parapatellar approach. After surgical procedures, arthrotomy incision was closed anatomically. For groups 3 and 4, $100 \mu \mathrm{L}$ PRP was applied on the joint space after closure.

The PRP was prepared from the blood of rats. In this process, $1 \mathrm{~mL}$ of the tail vein blood of each rat was obtained and centrifuged at $800 \mathrm{rpm}$ for 15 minutes once in citrated small tubes. Then, the platelet-rich portion was obtained and $100 \mu \mathrm{L}$ PRP was applied in the joint space immediately. No measurement and comparison of platelet or growth factor concentrations in the peripheral blood of the rats and PRP portions were performed. The HBO-treated group rats were taken to the experimental pressure chamber along with their cages. Rats were kept in the experimental pressure chamber for a total of 120 minutes, including 10 minutes of oxygen ventilation, 10 minutes of compression, 90 minutes of treatment depth, and 10 minutes of decompression. This treatment in HBO groups was continued for six days a week during a four-week period. ${ }^{[28]}$

For histopathological evaluation, all rats were sacrificed on the postoperative $30^{\text {th }}$ day, and the distal portion of each rat femur was removed and placed in a $10 \%$ formaldehyde solution. All specimens were then decalcified in 10\% nitric acid. An osteochondral block including defect was cut from the trochlea and embedded in a paraffin block. A thick section of $5 \mu \mathrm{m}$ was cut in the sagittal plane, which was mounted on slides and stained with hematoxylin-eosin. The same pathologist, who was blinded to the study groups, evaluated all of the tissue samples. Histological sections were scored by the same pathologist by using a modified version of the $\mathrm{O}^{\prime}$ Driscoll score (Table I). ${ }^{[33]}$ Seven categories were used in this scoring system. Categories 1 and 2 showed the degree of defect repair quantitatively and morphologically. Category 3 was designed for the surface architecture 
of the repair tissue, and category 4 evaluated the matrix production by staining proteoglycan with safranin O. Tidemark formation and integration of repaired tissue with surrounding cartilage were also

\begin{tabular}{|c|c|}
\hline \multicolumn{2}{|c|}{$\begin{array}{l}\text { TABLE I } \\
\text { Histological grading scale for defects in articular cartilage }\end{array}$} \\
\hline Category & Score (Points) \\
\hline $\begin{array}{l}\text { 1. Filling of defect relative } \\
\text { normal adjacent cartilage }\end{array}$ & 0 \\
\hline$>90 \%$ & 1 \\
\hline $75-90 \%$ & 2 \\
\hline $50-74 \%$ & 3 \\
\hline $25-49 \%$ & 4 \\
\hline$<25 \%$ & \\
\hline $\begin{array}{l}\text { 2. Cellular morphology (pe } \\
\text { chondrocytes) }\end{array}$ & 0 \\
\hline$>90 \%$ & 1 \\
\hline $75-90 \%$ & 2 \\
\hline $50-74 \%$ & 3 \\
\hline $25-49 \%$ & 4 \\
\hline Mostly fibroblast-like cel & \\
\hline 3. Surface architecture & \\
\hline Normal & 0 \\
\hline Slightly irregular & 1 \\
\hline Fibrillation & 2 \\
\hline Distrupted & 3 \\
\hline 4. Matrix staining with Safr & \\
\hline Normal & 0 \\
\hline Slightly reduced & 1 \\
\hline Moderately reduced & 2 \\
\hline Substantially reduced & 3 \\
\hline None & 4 \\
\hline 5. Tidemark formation & \\
\hline$>90 \%$ & 0 \\
\hline $75-90 \%$ & 1 \\
\hline $50-74 \%$ & 2 \\
\hline $25-49 \%$ & 3 \\
\hline$<25 \%$ & 4 \\
\hline $\begin{array}{l}\text { 5. Integration of repair tiss } \\
\text { articular cartilage }\end{array}$ & 0 \\
\hline Normal & 1 \\
\hline Decreased cellularity & 2 \\
\hline Small gap & 3 \\
\hline Discontinuity & \\
\hline 7. Percentage of new subc & \\
\hline$>90 \%$ & 0 \\
\hline $75-90 \%$ & 1 \\
\hline $50-74 \%$ & 2 \\
\hline $25-49 \%$ & 3 \\
\hline$<25 \%$ & 4 \\
\hline
\end{tabular}

scored in categories 5 and 6, respectively. Category 7 addressed the repair of subchondral bone. The data of morphological changes and percentages on this seven-category scale were converted into histological scores, which ranged from 0 to 26 points. The histological score of " 0 " was accepted as the perfect complete regeneration.

\section{Statistical analysis}

All the data were analyzed by using the IBM SPSS version 24.0 software (IBM Corp., Armonk, NY, USA). Microscopic findings of new cartilage characteristics were calculated for each group by using mean \pm standard deviations. The Kruskal-Wallis one-way analysis of variance test was used to analyze the difference among groups. Bonferroni-adjusted MannWhitney $U$ test was used in group comparisons. $P$ values of less than 0.05 were accepted as statistically significant.

\section{RESULTS}

All of the rats survived the study period. On the $30^{\text {th }}$ day, gross examination of osteochondral defects of the sacrificed rats showed a certain amount of closure in all of the defects. A microscopic examination revealed that the osteochondral defects of the control group rats were filled with fibrous tissue with incomplete surface epithelial development and the presence of irregularity (Figure 1a). The osteochondral defects of the HBO and PRP groups included cartilage and fibrous tissues, and there was very little formation of cartilage and new bone at the base. The surface was more clearly closed, and the regular proliferation of the surface epithelium was observed (Figure 1b). In group 4 rats with osteochondral defects in which $\mathrm{HBO}$ and PRP treatments were combined, there was a significant reduction in the depth of the defect. In addition, the formation of cartilage and new bone was observed on the edges, and the floor of the lesion and the surface became smooth (Figure 1c).

This study hypothesized that there would be better regeneration after the treatment with both $\mathrm{HBO}$ and PRP than with PRP or HBO alone; therefore, our analysis compared the HBO- and PRP-treated group with the other three groups. Also, the data were analyzed in order to investigate the relationship between the $\mathrm{HBO}$ and PRP groups.

By comparing the histological parameters among groups on the $30^{\text {th }}$ day, a statistically significant difference was noted in terms of mean scores $(p=0.01)$ (Table II). 

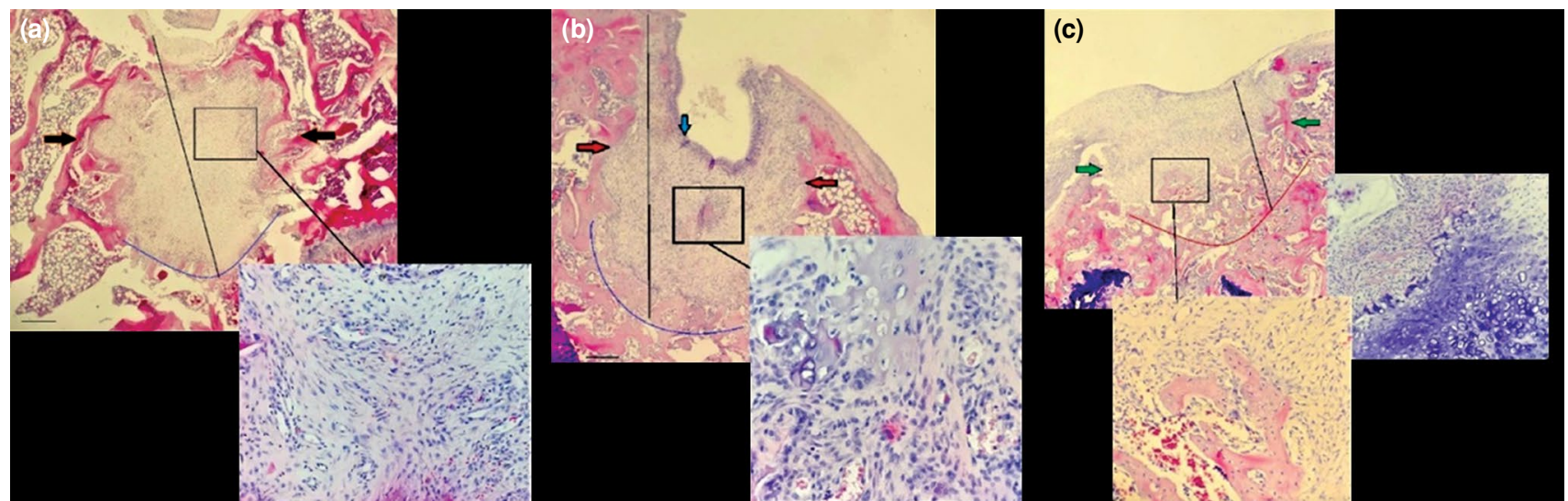

FIGURE 1. (a) Defect is filled with fibrous tissue with incomplete surface epithelial development. Irregularity is remarkable (40x magnification, hematoxylin-eosin [H-E] staining, control group). (b) Defect contains fibrous tissue and cartilage tissue, and there is very little formation of cartilage and new bone at base. Surface appears to be more clearly closed and surface epithelium is regularly proliferated (40x magnification, $\mathrm{H}$-E staining, hyperbaric oxygen [HBO] and platelet-rich plasma [PRP] groups). (c) Depth of defect is considerably reduced with cartilage from edges and base and new bone productions, as well as regular state of surface (40× magnification, H-E staining, HBO plus PRP group).

In the comparison between the groups, although the groups that were treated with either HBO or PRP alone regenerated significantly better than the control group ( $p=0.01$ ), no significant difference was found between the HBO- and PRP-treated groups ( $p>0.05$ ). The defects in group 4 (treated with both $\mathrm{HBO}$ and

\begin{tabular}{|c|c|c|c|}
\hline & istc & $\begin{array}{l}\text { TABLE II } \\
\text { ical grading scores }\end{array}$ & \\
\hline & & Histological grading score & \\
\hline Group & $\mathrm{n}$ & Mean $\pm S D$ & $p$ \\
\hline Control & 8 & $16.7 \pm 1.4$ & \\
\hline $\mathrm{HBO}$ & 8 & $8.3 \pm 2.1$ & 01 \\
\hline PRP & 8 & $9.4 \pm 1.7$ & 0.01 \\
\hline $\mathrm{HBO}+\mathrm{PRP}$ & 8 & $5.0 \pm 1.2$ & \\
\hline
\end{tabular}

\begin{tabular}{|lc|}
\multicolumn{2}{|c|}{$\begin{array}{c}\text { TABLE III } \\
\text { Intergroup comparisons with Bonferroni adjusted } \\
\text { Mann-Whitney U test }\end{array}$} \\
\hline Groups & $p$ \\
\hline (HBO+PRP)/HBO & 0.04 \\
(HBO+PRP)/PRP & 0.006 \\
(HBO+PRP)/Control & 0.01 \\
HBO/PRP & $>0.05$ \\
HBO/Control & 0.01 \\
PRP/Control & 0.01 \\
\hline HBO: Hyperbaric oxygen; PRP: Platelet-rich plasma. \\
\hline
\end{tabular}

PRP) regenerated significantly better than the control group, the HBO-treated group alone, and the PRPtreated group alone $(\mathrm{p}=0.01)$ (Table III).

\section{DISCUSSION}

Various studies in the literature have reported the effects of HBO and PRP treatment on tissue healing by different mechanisms. This research statistically demonstrated the benefits of these two treatments on regeneration, separately and combined, in the osteochondral defects of rats, which happens to be the primary hypothesis of this study.

The rates of type 2 collagen or poor quality type 1 collagen in the regenerated tissue were not determined by immunohistochemical examinations.

During the regeneration process of acute osteochondral defect, following processes occur: the formation of hematoma after local bleeding, the migration of mesenchymal stem cells from the underlying bone marrow, the transformation of these stem cells to chondrocytes, their proliferation, and filling of the defect with fibrocartilage instead of a better quality hyaline cartilage. In this regeneration process, the role of PRP is very remarkable because of the anabolic effects of growth factors, such as platelet-derived growth factor, endothelial growth factor, insulin-like growth factor, transforming growth factor beta 1, vascular endothelial growth factor, hepatocyte growth factor, and basic fibroblast growth factor, in its content and synergistic effects on regeneration in the damaged cartilage tissue. Unlike single-targeted biological therapies, PRP is one of 
the rare treatment options that have superiority in providing the hemostasis of synovial fluid because it contains many bioactive factors. ${ }^{[23-27]}$ In acute cartilage damage, if the defect reaches the subchondral bone, the amount of these growth factors and mesenchymal stem cells increases in the medium, but healing does not occur in chronic and incomplete defects. Therefore, microfracture surgery is used to stimulate the process of regeneration. Platelet-rich plasma has been widely used in previous animal ${ }^{[9-13]}$ and human studies, ${ }^{[14-21]}$ which demonstrated that hyaline cartilage-like regeneration was induced histologically and biomechanically by increasing the production of proteoglycan and collagen from chondrocytes. ${ }^{[8]}$ Although the control group in this study showed some improvement in acute osteochondral defects, based on our results, it can be concluded that increasing the amount of bioactive substance in the environment with PRP leads to a better regeneration process.

The HBO treatment is a method of treatment that involves oxygen inhalation at pressures higher than 1 atmosphere in a closed system. The application of $\mathrm{HBO}$ increases the levels of dissolved oxygen in tissues and plasma. Patients are treated with a direct effect of pressure and increased levels of dissolved oxygen in tissues by keeping them in a hyperbaric cabinet. ${ }^{[28,29]}$ The partial pressure of oxygen in injured tissues is about $5-15 \mathrm{mmHg}$. This hypoxic value is not sufficient to perform the necessary synthesis in the healing of wounds. Although it is well known that the oxygen concentration in the bone increases three fold at 2-2.4 atmospheric pressure of $\mathrm{HBO}$ and tissues require approximately $30-33 \mathrm{mmHg}$ oxygen pressure for the healing of wounds, there is no clear information about the ideal oxygen concentration for cartilage regeneration. ${ }^{[30]}$ Fibroblast proliferation and collagen production increase during hyperoxygenation, whereas subsequent relative hypoxia stimulates the process of angiogenesis. It also stimulates the process of angiogenesis by increasing the oxygen gradient between the wound and surrounding tissue during the HBO treatment. Increased fibronectin production also results in neovascularization. In the treatment of chronic wounds, osteoradionecrosis, and other radiation damages, this effect is used to increase graft and flap survival. ${ }^{[31]}$ Chen et al. ${ }^{[22]}$ compared HBO and fibrin in the regeneration of osteochondral defects in rabbit knees, which showed significantly better cartilage regeneration than the control group, and they even concluded that the combination of fibrin and $\mathrm{HBO}$ showed no extra synergistic effect. To our knowledge, this is the first study that describes a synergistic effect of $\mathrm{HBO}$ and PRP on the regeneration of osteochondral defects.
Although the data on the single use of PRP and $\mathrm{HBO}$ treatments are well documented, there are very few studies on how these two methods can affect each other. Shaw et al. ${ }^{[34]}$ exposed human platelets to $\mathrm{HBO}$ and noted a significant increase in platelet aggregation and protein release as compared to the normobaric medium.

Another set of positive results with the combination of PRP and HBO was achieved by Neves et al., ${ }^{[35]}$ who showed an increased healing process in the bones of rabbits with fibula defects via the combined application of $\mathrm{HBO}$ and autologous platelet concentrates (APCs). Neves et al. ${ }^{[35]}$ showed an enhanced percentage of collagen and decreased lesion thickness with the combined use of $\mathrm{HBO}$ and APC as compared to the control group, APC group, and $\mathrm{HBO}$ group.

In the animal study of Schneppendahl et al., ${ }^{[36]}$ where HBO and PRP had a synergistic effect, they compared the iliac autograft application by adding $\mathrm{HBO}$ and PRP to the monocortical defects created in the radius bone of rabbits. With this study, they demonstrated that this combination enhances the osteoinductive capacity of the autograft and angiogenesis. Although our study concerns cartilage regeneration in ostechondral lesions, these synergistic effects and mechanisms can support the results of our study.

There are some limitations associated with this experiment. All osteochondral defects created in our study were performed on the same patellofemoral region of the knee in all of the rats but were not tested in different load-bearing areas of the knee. In addition, sacrification was not performed in different time periods in order to follow the regeneration process step by step, but only the total amount of regeneration at the end of the $30^{\text {th }}$ day was examined. Macroscopic and histological evaluations were performed; however, outcomes such as function, biomechanical properties, or the long-term survival of regenerated cartilage were not studied.

Technically, PRP of very different quality and content can be prepared and this does not have precise standards in humans and animal experiments. Another limitation of this study is that the analysis of the PRP could not be performed due to the very limited amount of blood samples. The rates of type 2 collagen or poor quality type 1 collagen in the regenerated tissue were not determined by immunohistochemical examinations.

In conclusion, the results of this study showed a synergistic effect of HBO and PRP on knee cartilage 
regeneration that was not compared in the literature before. The results of our study also support a limited number of data reports available in the literature. Although the details are not well understood, the aggregation and activation of growth factors released from platelets whose activation is increased in the hyperbaric environment may explain this synergistic effect. This may result in a better regeneration than the effect of PRP or HBO alone. Of course, further studies are needed to demonstrate this effect more clearly and determine the optimal PRP and HBO standards for osteochondral regeneration.

\section{Declaration of conflicting interests}

The authors declared no conflicts of interest with respect to the authorship and/or publication of this article.

\section{Funding}

The authors received no financial support for the research and/or authorship of this article.

\section{REFERENCES}

1. Alford JW, Cole BJ. Cartilage restoration, part 1: basic science, historical perspective, patient evaluation, and treatment options. Am J Sports Med 2005;33:295-306.

2. Burks RT, Greis PE, Arnoczky SP, Scher C. The use of a single osteochondral autograft plug in the treatment of a large osteochondral lesion in the femoral condyle: an experimental study in sheep. Am J Sports Med 2006;34:247-55.

3. Sezgin EA, Atik OŞ. Are orthobiologics the next chapter in clinical orthopedics? A literature review. Eklem Hastalik Cerrahisi 2018;29:110-6.

4. Sams AE, Nixon AJ. Chondrocyte-laden collagen scaffolds for resurfacing extensive articular cartilage defects. Osteoarthritis Cartilage 1995;3:47-59.

5. Newman AP. Articular cartilage repair. Am J Sports Med 1998;26:309-24.

6. Laskin RS. The classic: total condylar knee replacement in patients who have rheumatoid arthritis. A ten-year followup study. 1990. Clin Orthop Relat Res 2008;466:2589-96.

7. Koskinen E, Eskelinen A, Paavolainen P, Pulkkinen P, Remes V. Comparison of survival and cost-effectiveness between unicondylar arthroplasty and total knee arthroplasty in patients with primary osteoarthritis: a follow-up study of 50,493 knee replacements from the Finnish Arthroplasty Register. Acta Orthop 2008;79:499-507.

8. Krüger JP, Hondke S, Endres M, Pruss A, Siclari A, Kaps C. Human platelet-rich plasma stimulates migration and chondrogenic differentiation of human subchondral progenitor cells. J Orthop Res 2012;30:845-52.

9. Nishimori M, Deie M, Kanaya A, Exham H, Adachi N, Ochi M. Repair of chronic osteochondral defects in the rat. A bone marrow-stimulating procedure enhanced by cultured allogenic bone marrow mesenchymal stromal cells. J Bone Joint Surg Br 2006;88:1236-44.

10. Sun Y, Feng Y, Zhang CQ, Chen SB, Cheng XG. The regenerative effect of platelet-rich plasma on healing in large osteochondral defects. Int Orthop 2010;34:589-97.
11. Kon E, Filardo G, Delcogliano M, Fini M, Salamanna F, Giavaresi G, et al. Platelet autologous growth factors decrease the osteochondral regeneration capability of a collagen-hydroxyapatite scaffold in a sheep model. BMC Musculoskelet Disord 2010;11:220.

12. Milano G, Deriu L, Sanna Passino E, Masala G, Manunta A, Postacchini R, et al. Repeated platelet concentrate injections enhance reparative response of microfractures in the treatment of chondral defects of the knee: an experimental study in an animal model. Arthroscopy 2012;28:688-701.

13. Milano G, Deriu L, Sanna Passino E, Masala G, Saccomanno MF, Postacchini R, et al. The effect of autologous conditioned plasma on the treatment of focal chondral defects of the knee. An experimental study. Int J Immunopathol Pharmacol 2011;24:117-24.

14. Qi YY, Chen X, Jiang YZ, Cai HX, Wang LL, Song XH, et al. Local delivery of autologous platelet in collagen matrix simulated in situ articular cartilage repair. Cell Transplant 2009;18:1161-9.

15. Kon E, Mandelbaum B, Buda R, Filardo G, Delcogliano M, Timoncini A, et al. Platelet-rich plasma intra-articular injection versus hyaluronic acid viscosupplementation as treatments for cartilage pathology: from early degeneration to osteoarthritis. Arthroscopy 2011;27:1490-501.

16. Kon E, Buda R, Filardo G, Di Martino A, Timoncini A, Cenacchi A, et al. Platelet-rich plasma: intra-articular knee injections produced favorable results on degenerative cartilage lesions. Knee Surg Sports Traumatol Arthrosc 2010;18:472-9.

17. Filardo G, Kon E, Di Martino A, Di Matteo B, Merli ML, Cenacchi A, et al. Platelet-rich plasma vs hyaluronic acid to treat knee degenerative pathology: study design and preliminary results of a randomized controlled trial. BMC Musculoskelet Disord 2012;13:229.

18. Patel S, Dhillon MS, Aggarwal S, Marwaha N, Jain A. Treatment with platelet-rich plasma is more effective than placebo for knee osteoarthritis: a prospective, double-blind, randomized trial. Am J Sports Med 2013;41:356-64.

19. Lee GW, Son JH, Kim JD, Jung GH. Is platelet-rich plasma able to enhance the results of arthroscopic microfracture in early osteoarthritis and cartilage lesion over 40 years of age? Eur J Orthop Surg Traumatol 2013;23:581-7.

20. Bellamy N, Campbell J, Robinson V, Gee T, Bourne R, Wells G. Viscosupplementation for the treatment of osteoarthritis of the knee. Cochrane Database Syst Rev 2006;2:CD005321.

21. Wang CT, Lin J, Chang CJ, Lin YT, Hou SM. Therapeutic effects of hyaluronic acid on osteoarthritis of the knee. A meta-analysis of randomized controlled trials. J Bone Joint Surg [Am] 2004;86:538-45.

22. Chen AC, Lee MS, Lin SS, Pan LC, Ueng SW. Augmentation of osteochondral repair with hyperbaric oxygenation: a rabbit study. J Orthop Surg Res 2010;5:91.

23. Sundman EA, Cole BJ, Karas V, Della Valle C, Tetreault MW, Mohammed HO, et al. The anti-inflammatory and matrix restorative mechanisms of platelet-rich plasma in osteoarthritis. Am J Sports Med 2014;42:35-41.

24. Spreafico A, Chellini F, Frediani B, Bernardini G, Niccolini $\mathrm{S}$, Serchi T, et al. Biochemical investigation of the effects of human platelet releasates on human articular chondrocytes. J Cell Biochem 2009;108:1153-65.

25. Park KH, Na K. Effect of growth factors on chondrogenic differentiation of rabbit mesenchymal cells embedded in injectable hydrogels. J Biosci Bioeng 2008;106:74-9. 
26. Solorio LD, Dhami CD, Dang PN, Vieregge EL, Alsberg E. Spatiotemporal regulation of chondrogenic differentiation with controlled delivery of transforming growth factor- $\beta 1$ from gelatin microspheres in mesenchymal stem cell aggregates. Version 2. Stem Cells Transl Med 2012;1:632-9.

27. Boswell SG, Cole BJ, Sundman EA, Karas V, Fortier LA. Platelet-rich plasma: a milieu of bioactive factors. Arthroscopy 2012;28:429-39.

28. Sahni T, Hukku S, Jain M, Prasad A, Prasad R, Singh K. Recent Advances in Hyperbaric Oxygen Therapy. Medicine Update 2014;14: 632-9.

29. Chander Y, Misra RN, Rai R. Hyperbaric oxygen therapy [HBOT]. Med J Armed Forces India 1999;55:89-90.

30. Strauss MB. Role of hyperbaric oxygen therapy in acute ischemic and crush injuries. An orthopedic perspective. Hyperbaric Oxygen Rev 1981;2:87-106.

31. Aguiar P, Amaral C, Rodrigues A, de Souza AH. A diabetic foot ulcer treated with hydrogel and hyperbaric oxygen therapy: a case study. J Wound Care 2017;26:692-5.
32. Atik OŞ. Is there something new and interesting in my article? Eklem Hastalik Cerrahisi 2019;30:69.

33. O'Driscoll SW, Keeley FW, Salter RB. The chondrogenic potential of free autogenous periosteal grafts for biological resurfacing of major full-thickness defects in joint surfaces under the influence of continuous passive motion. An experimental investigation in the rabbit. J Bone Joint Surg [Am] 1986;68:1017-35.

34. Shaw FL, Winyard PG, Smerdon GR, Bryson PJ, Moody AJ, Eggleton P. Hyperbaric oxygen treatment induces platelet aggregation and protein release, without altering expression of activation molecules. Clin Biochem 2009;42:467-76.

35. Neves PC, Abib Sde C, Neves RF, Pircchio O, Saad KR, Saad $\mathrm{PF}$, et al. Effect of hyperbaric oxygen therapy combined with autologous platelet concentrate applied in rabbit fibula fraction healing. Clinics (Sao Paulo) 2013;68:1239-46.

36. Schneppendahl J, Jungbluth P, Sager M, Benga L, Herten M, Scholz A, et al. Synergistic effects of $\mathrm{HBO}$ and PRP improve bone regeneration with autologous bone grafting. Injury 2016;47:2718-25. 